\title{
Activation of Molecular Oxygen by a Molybdenum(IV) Imido Com- pound
}

\author{
Niklas Zwettler, ${ }^{\text {a }}$ Nidhi Grover, ${ }^{\text {a }}$ Ferdinand Belaj, ${ }^{a}$ Karl Kirchner ${ }^{b}$ and Nadia C. Mösch-Zanetti*a \\ a. Institute of Chemistry, Inorganic Chemistry, University of Graz, Schubertstrasse 1, 8010 Graz, Austria \\ b. Institute of Applied Synthetic Chemistry, Vienna University of Technology, Getreidemarkt 9, 1060 Vienna, Austria
}

Supporting Information Placeholder

\begin{abstract}
Activation of molecular dioxygen at a Mo(IV) imido compound led to the isolation and full characterization of a remarkably stable transition metal imido peroxido complex.
\end{abstract}

The use of molecular oxygen as the primary oxidant in oxidation reactions is of fundamental interest in view of the urgent desire for the development of green chemical processes. ${ }^{1}$ At present, there is a growing interest in finding alternatives to precious metals, mainly for economic and environmental reasons. ${ }^{2,3}$ Molybdenum, being a non-precious, earth-abundant, non-toxic metal represents an ideal candidate for abovementioned task, ${ }^{4}$ as evident from the widespread use of Mo compounds in oxygenation chemistry. ${ }^{5}$ We have previously investigated high oxidation state molybdenum complexes with various $\mathrm{O}, \mathrm{N}$ ligands for the catalytic oxidation of olefins. ${ }^{6-10}$ However, to date, the facilitation of molecular oxygen as oxidant remains elusive. Whereas the activation of molecular oxygen by molybdenum(IV) complexes has been established by our group and others, concomitant oxygen atom transfer is restricted to very few substrates. ${ }^{11-16}$

All molybdenum complexes capable of activating molecular oxygen are of the general structure $\left[\mathrm{MoOL}_{n}\right]$ and lead to the formation of $\left[\mathrm{MoO}\left(\mathrm{O}_{2}\right) \mathbf{L}_{n}\right]$ complexes, with $\mathbf{L}$ being either $\mathrm{CN}^{-}$or bidentate monoanionic ligands. The oxido ligand renders the metal center electron poor, thus leading to strong $\sigma$-bonds but simultaneously inhibiting any $\pi$-backbonding to the peroxido unit. In theory, such backbonding marks an important contribution to weaken the peroxide $\mathrm{O}-\mathrm{O}$ bond. For this reason, we envisioned to exchange the "spectator" oxido ligand with an electron donating imido group to leave more electron density at the metal to increase $\pi$-backbonding, possibly enabling the transfer of the peroxido oxygen atoms. ${ }^{17-19}$

In contrast to oxido peroxido complexes, which are usually easily accessible via the reaction of $\mathrm{MoO}_{3}$ with $\mathrm{H}_{2} \mathrm{O}_{2}$ and appropriate ligand addition, ${ }^{20,21}$ the substance class of imido peroxido complexes is so far only accessible via molecular oxygen activation and has not been described.
Generally, no transition metal complex bearing an imido and a peroxido ligand has been disclosed to date. Herein, we present the synthesis of the first molybdenum(VI) imido peroxido complex and the full characterization of all involved species by experimental and theoretical means. Furthermore first studies on the reactivity of this species are reported, obtaining valuable insight into the electronic influence on the bonding situation at the molybdenum center.

The oxido imido complexes $\left[\mathrm{MoO}(\mathrm{N} t \mathrm{Bu})(\mathbf{L})_{2}\right]$, $\mathbf{1 a}$ and $\mathbf{1 b}$, were prepared by reacting $\left[\mathrm{MoO}(\mathrm{N} t \mathrm{Bu}) \mathrm{Cl}_{2}(\mathrm{dme})\right]^{22-24}$ with the respective iminophenolate ligands $\mathrm{HL1}^{25}(\mathrm{R}=\mathrm{Me})$ or $\mathbf{H L 2}(\mathrm{R}=t \mathrm{Bu}),{ }^{26}$ as shown in Scheme 1.

NMR spectroscopic data of $\mathbf{1 a}$ and $\mathbf{1 b}$ reveals the presence of two isomers in solution (Scheme 1), reminiscent of previously reported dioxido molybdenum compounds. The N,N isomer (referring to the atoms in trans position to oxido and imido ligand) is typically the dominant form and the N,O isomer is primarily formed due to increasing steric congestion. ${ }^{7,16}$ Theoretical calculations reveal the $\mathrm{N}, \mathrm{N}$ isomer being energetically favored by only 1.6 $\mathrm{kcal} / \mathrm{mol}$ in the case of 1a, corroborating the isomeric equilibrium. Interestingly, single-crystal X-ray diffraction analysis reveals that the two compounds crystallized in different isomeric arrangements; in the case of 1a the putative minor isomer in solution crystallized (Figures S17 and S18, SI).

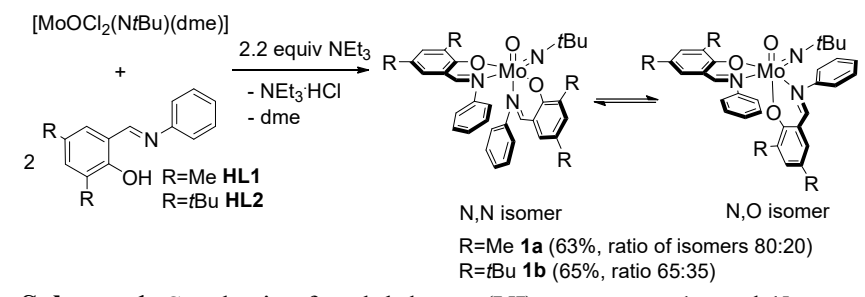

Scheme 1. Synthesis of molybdenum(VI) precursors $\mathbf{1 a}$ and $\mathbf{1 b}$. 


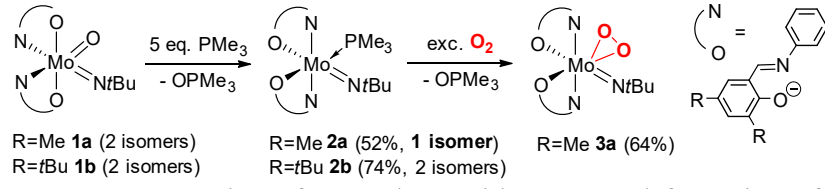

Scheme 2. Reaction of $\mathbf{1 a}$ and $\mathbf{1 b}$ with $\mathrm{PMe}_{3}$ and formation of complex $\mathbf{3 a}$ via molecular oxygen activation by $\mathbf{2} \mathbf{a}$.

Two-electron reduction with $\mathrm{PMe}_{3}$ generates the phosphane coordinated molybdenum(IV) imido complexes $\left[\mathrm{Mo}(\mathrm{N} t \mathrm{Bu})\left(\mathrm{PMe}_{3}\right)(\mathbf{L})_{2}\right](\mathbf{2} \mathbf{a}, \mathrm{R}=\mathrm{Me}$ and $\mathbf{2} \mathbf{b}, \mathrm{R}=t \mathrm{Bu})$, while no reaction was observed with the bulky phosphane $\mathrm{PPh}_{3}$ (Scheme 2).

Proton NMR spectroscopy revealed the expected isomeric mixture for compound $\mathbf{2 b}$ (approx. 60:40), whereas only one isomer was observed for complex $\mathbf{2 a}$. The isomerically pure complex $\mathbf{2 a}$, equipped with the 2,6-dimethyl substituted phenolate ligands, subsequently reacted cleanly with molecular $\mathrm{O}_{2}$ to form the desired molybdenum(VI) imido peroxido compound $\left[\mathrm{Mo}(\mathrm{N} t \mathrm{Bu})\left(\eta^{2}-\right.\right.$ $\left.\left.\mathrm{O}_{2}\right)(\mathbf{L 1})_{2}\right]$, 3a. Although complex 2b was also reactive towards dioxygen, significant decomposition was observed during the reaction, which prevented a clean isolation of the respective peroxido species. For complex 3a, only one isomer was observed via NMR spectroscopy, and single-crystal X-ray diffraction analysis of the compound identified the isomeric form as the $\mathrm{O}, \mathrm{O}$ arrangement. This is in good agreement with previously reported iminophenolate oxido peroxido compounds, ${ }^{15,16}$ where it has been observed that oxygen activation always is concomitant to an isomeric rearrangement. Such a rearrangement is likely hampered by the additional sterically demanding $t \mathrm{Bu}$ groups at the aromatic rings in $\mathbf{2 b}$, thus preventing a clean reaction. Interestingly, the reduction of a pyrrol imine based oxido imido complex with $\mathrm{PMe}_{3}$ cleanly led to an isomerically pure compound with retained stereochemistry during the OAT step. ${ }^{27}$

IR spectroscopy reveals the $\mathrm{Mo}=\mathrm{O}$ bands for $\mathbf{1 a}$ and $\mathbf{1 b}$ at 878 (calc.: $902^{\dagger}$, Figure S19, SI) and $890 \mathrm{~cm}^{-1}$, respectively, which is 20-30 wavenumbers lower in energy compared to stretching frequencies observed for previously reported Mo oxido imido compounds. ${ }^{19,27}$ This corroborates a weakened $\mathrm{Mo}=\mathrm{O}$ bond, as also observed by X-ray crystallography (vide infra). The $\mathrm{v}_{(\mathrm{O}-\mathrm{O})}$ band in 3a is observed at $924 \mathrm{~cm}^{-1}$ (calc.: 1007†, Figure S20, SI), comparable to other weakly activated (O-O) bonds in transition metal peroxides. ${ }^{28}$ The $v_{(\mathrm{O}-\mathrm{O})}$ band for the related oxido peroxido complex $\left[\mathrm{MoO}\left(\eta^{2}-\mathrm{O}_{2}\right)(\mathbf{L 2})_{2}\right], \mathbf{5}^{16}$ is assigned at $927 \mathrm{~cm}^{-1}$, in agreement with the virtually identical stretching frequencies computed for 3a and 3a' (calc. for 3a': $1005 \mathrm{~cm}^{-1 \dagger}$, Figure S21, SI), suggesting that the donating nature of the imido ligand does not lead to the envisioned $\pi$-backbonding.

Peroxido complex 3a reacts with $\mathrm{PMe}_{3}$ as limiting reactant $(0.25$ equiv), slowly leading to a mixture of $\mathbf{1 a}$ and unreacted $\mathbf{3 a}$ (Scheme 3). This is in contrast to the related oxido peroxido compound where the higher reactivity of the dioxido compound prevented its observation during OAT. ${ }^{15,16}$ However, addition of a further equivalent of $\mathrm{PMe}_{3}$ to the above mixture led to the expected mixture of $\mathbf{3 a}$ and $\left[\mathrm{Mo}(\mathrm{N} t \mathrm{Bu})\left(\mathrm{PMe}_{3}\right)(\mathbf{L 1})_{2}\right], 2 \mathbf{a}$ (Scheme 3).

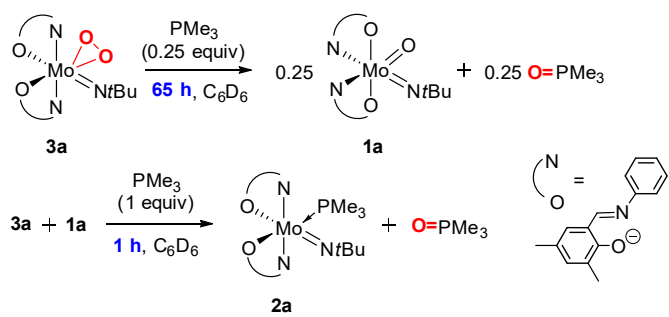

Scheme 3. Reactivity of complex 3a with $\mathrm{PMe}_{3}$.

This suggests a similar but generally lower reactivity of the imido peroxide system. Presumably for this reason, complexes 1a and 1b, $\left[\mathrm{MoO}(\mathrm{N} t \mathrm{Bu})(\mathbf{L})_{2}\right]$, both were essentially inactive under catalytic conditions, ${ }^{\S}$ which is in contrast to the dioxido analogue $\left[\mathrm{MoO}_{2}(\mathbf{L 2})_{2}\right], 4{ }^{16}$ This may be attributed to the remarkable stability of the corresponding peroxides towards reduction. Furthermore, we did not observe a transfer of the imido group to the phosphane substrate for $\mathbf{1 a}, \mathbf{1} \mathbf{b}$ or the peroxide $\mathbf{3} \mathbf{a}$, suggesting that the imido transfer reaction is also energetically disfavoured. ${ }^{29}$ Oxygen atom transfer to bulkier phosphanes or more challenging substrates as alkenes was not successful, the latter being in line with previous observations. ${ }^{15,16}$

Single-crystal X-ray diffraction analysis of 3a reveals similar geometric features to previously described dioxido and oxido peroxido complexes. ${ }^{6-8,15,16,30,31}$ In general, the more electron donating imido group leads to a slight elongation of $\mathrm{Mo}=\mathrm{O}$ as well as Mo-(O-O) bonds in comparison to a second oxido ligand, reflecting weaker $\sigma$-bonds to the less electrophilic metal center (Table 1). The O-O bond lengths on the other hand are essentially identical (1.4399(17) in 3a vs. 1.4425(18) in 5), ${ }^{16}$ further corroborating an absent $\pi$-backbonding to the peroxido unit.

Table 1. Comparison of selected bond lengths for complexes 1a, $\mathbf{1 b}, \mathbf{3 a}$ as well as $\left[\mathrm{MoO}_{2}(\mathbf{L 2})_{2}\right], \mathbf{4}^{16}$ and $\left[\mathrm{MoO}\left(\eta^{2}-\mathrm{O}_{2}\right)(\mathbf{L 2})_{2}\right], \mathbf{5}^{16}$

\begin{tabular}{lccccc}
\hline & $\mathbf{1 a}$ & $\mathbf{1 b}$ & $\mathbf{3 a}$ & $\mathbf{4}^{16}$ & $\mathbf{5}^{16}$ \\
\hline $\mathrm{Mo}=\mathrm{O}$ & $1.727(6)$ & $1.7198(18)$ & - & $1.707(3)$, & $1.6928(13)$ \\
& & & & $1.706(3)$ & \\
$\mathrm{Mo}=\mathrm{N} t \mathrm{Bu}$ & $1.740(6)$ & $1.739(2)$ & $1.7261(15)$ & - & - \\
$\mathrm{Mo}-(\mathrm{O}-\mathrm{O})$ & - & - & $1.9764(13)$, & - & $1.9581(13)$, \\
& & & $1.9754(13)$ & & $1.9301(13)$ \\
$(\mathrm{O}-\mathrm{O})$ & - & - & $1.4399(17)$ & - & $1.4425(18)$ \\
\hline
\end{tabular}

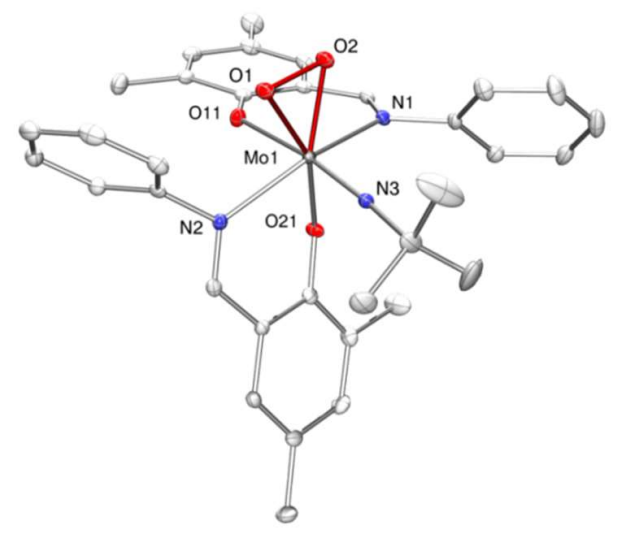

Figure 1. Molecular view (50\% probability level) of imido peroxido species $\mathbf{3 a} ; \mathrm{H}$ atoms as well as solvent molecules are omitted for clarity reasons, bonds incorporated in the peroxido moiety are depicted in red. 
Comparison of the molecular structures of the $\left[\mathrm{MoO}(\mathrm{N} t \mathrm{Bu}) \mathbf{L}_{2}\right]$ complexes 1a and $\mathbf{1 b}$ (Figures S17 and S18, SI) revealed a further interesting observation as their geometric arrangement in solid state is different, namely N,O in $\mathbf{1 a}$ and N,N in $\mathbf{1 b}$. This corroborates previous postulations about the two isomeric forms of related molybdenum dioxido complexes. ${ }^{7,16}$

The geometries and electronic structures of the imido complexes 1a and 3a were investigated by means of DFT/PBE0 calculations. $^{32,33}$ For comparison reasons, such calculations were also executed for a corresponding oxido derivative 3a' of the structure $\left[\mathrm{MoO}\left(\eta^{2}-\mathrm{O}_{2}\right)(\mathbf{L 1})_{2}\right]$. Theoretical details can be found in the supporting information. The optimized structures of complexes 1a (2 isomeric forms), 3a and 3a' as well as the corresponding frontier orbitals of 3a and 3a' are provided in Figures 2 and S22-S24 (SI), respectively. The pattern of the orbitals obtained is typical of $\operatorname{Mo}(\mathrm{VI}) \mathrm{d}^{0}$ complexes with a pseudo-octahedral geometry, i.e., all five d-orbitals are essentially empty. Comparison of the orbital geometries and energies of the two systems reveals that all dorbitals other than the " $\mathrm{z}$ " orbital, are lower in energy and thus more accessible in the oxido peroxido compound 3a'. Furthermore, in the imido complex 3a, only the "xy" orbital shows significant mixing with the peroxido ligand orbitals whereas in $\mathbf{3 a}$ ' all orbitals except the " $\mathrm{z}$ " peroxide (Figures 2, S23 and S24).Both observations are in good agreement with the pronounced stability of compound 3a towards reduction. With respect to the atomic charges (NPA population analysis $)^{34-38}$ it is evident that the imido ligand in 3a is a significantly better electron donor, establishing a stronger coordination and providing an electron richer metal center compared to the oxido ligand in 3a' (Wiberg indices $^{39}$ are 1.99 for the $\mathrm{Mo}=\mathrm{N}$ (imide) bond in 3a and 1.85 for the $\mathrm{Mo}=\mathrm{O}$ bond in $\mathbf{3 a}$ '). This is also reflected by the metal charges which are 1.42 (3a) and $1.64\left(\mathbf{3 a}^{\prime}\right)$, as well as the corresponding ligand charges ( -0.11 for the imido and -0.46 for the oxido ligand, respectively).

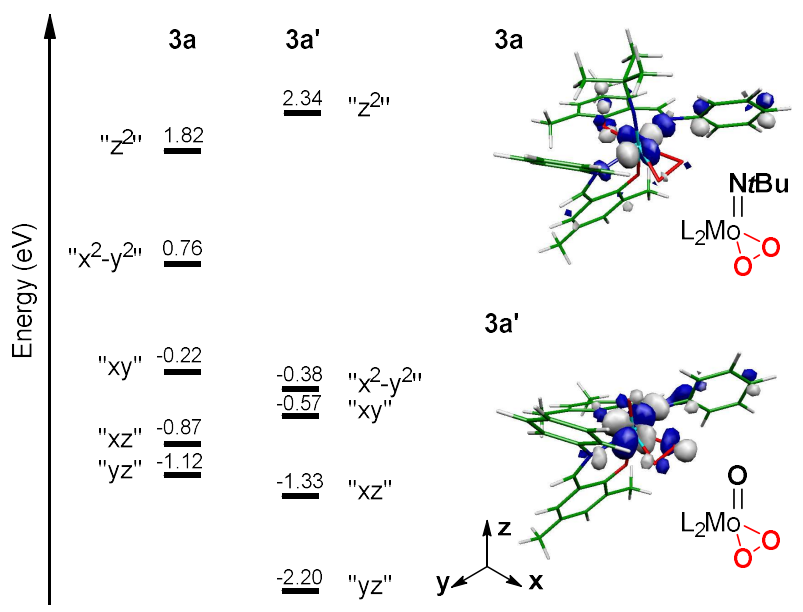

Figure 2. DFT/PBE0 calculated frontier orbital pattern for $\mathbf{3 a}$ and 3a', energy values in electron volts (left); calculated " $\mathrm{x}^{2}-\mathrm{y}^{2}$ " orbitals of 3a and 3a' showing the different orbital localization at the peroxido unit (right).
In conclusion, the first transition metal imido peroxido complex is conveniently accessible via molecular oxygen activation at a molybdenum(IV) imido precursor. The complex has been fully characterized by spectroscopic means and theoretical considerations. Single crystal X-ray diffraction analysis as well as theoretical calculations both shows a larger electron donation by the imido ligand in comparison to an oxido moiety that leads to a less electrophilic metal center and thus weaker $\sigma$-bonds to the peroxido ligand.

However, the increased electron density is insufficient to facilitate $\pi$-backbonding to the peroxido unit in order to weaken the $\mathrm{O}$ $\mathrm{O}$ bond. While it is possible that the low reactivity of the system is ultimately also a result of steric congestion, the observations presented herein clearly suggest that the weaker Mo-O $\sigma$-bonds do not have a positive effect on the ability to transfer the peroxido oxygens. The envisioned $\pi$-backbonding to the peroxido unit could not be realized by the larger electron density at the metal center, in contrary, the lower electrophilicity actually hampers the reduction step from $\mathrm{Mo}(\mathrm{VI})$ to $\mathrm{Mo}(\mathrm{IV})$ by raising the frontier orbital energies. A feasible method to enhance reactivity might be to make the metal center even more electropositive, e.g. by the incorporation of electron withdrawing groups in the ligands, a matter which is currently under investigation. The results presented herein provide for the first time very important information about the properties of imido supported peroxido complexes and offer new directions for future ligand and complex design, also for the stabilization of notoriously unstable transition metal peroxides.

\section{ASSOCIATED CONTENT}

\section{Supporting Information}

Supporting Information (SI) available: Experimental, crystallographic and theoretical details. The Supporting Information is available free of charge on the ACS Publications website. CCDC 1560457-1560459 contain the supplementary crystallographic data for this paper. These data can be obtained free of charge from The Cambridge Crystallographic Data Centre via www.ccdc.cam.ac.uk/data_request/cif.

\section{AUTHOR INFORMATION}

\section{Corresponding Author}

Nadia C. Mösch-Zanetti

nadia.moesch@uni-graz.at

\section{Author Contributions}

\$ These authors contributed equally.

\section{Notes}

The authors declare no competing financial interests.

\section{ACKNOWLEDGMENT}

Financial support by the Austrian Science Fund (FWF) (grant number P26264) and NAWI Graz is gratefully acknowledged. 


\section{REFERENCES}

$\uparrow$ Calculated values for the vibrational bands were scaled by a factor of 0.9536 , according to literature..$^{40}$

$\S$ Used conditions were $1 \mathrm{~mol} \%$ catalyst with excess of dry $\mathrm{O}_{2}$ gas ( 1.5 atm) in $\mathrm{C}_{6} \mathrm{D}_{6}$ at room temperature. Blank experiments under identical conditions but without catalysts led to conversions $<5 \%$ for both $\mathrm{PMe}_{3}$ and $\mathrm{PPh}_{3}$.

(1) Modern Oxidation Methods; Bäckvall, J.-E., Ed.; WileyVCH: Weinheim, Germany, 2010.

(2) Kück, J. W.; Reich, R. M.; Kühn, F. E. Molecular Epoxidation Reactions Catalyzed by Rhenium, Molybdenum, and Iron Complexes. Chemical Record 2016, 16, 349-364.

(3) Kück, J. W.; Raba, A.; Markovits, I. I. E.; Cokoja, M.; Kühn, F. E. Epoxidation of Olefins Catalyzed by a Molecular Iron N Heterocyclic Carbene Complex: Influence of Reaction Parameters on the Catalytic Activity. ChemCatChem 2014, 6, 1882-1886.

(4) Bullock, R. M. Catalysis without Precious Metals; WileyVCH: Weinheim, Germany, 2010.

(5) Hauser, S. A.; Cokoja, M.; Kühn, F. E. Epoxidation of olefins with homogeneous catalysts - quo vadis? Catal. Sci. Technol. 2013, 3, 552-561.

(6) Lyashenko, G.; Saischek, G.; Judmaier, M. E.; Volpe, M.; Baumgartner, J.; Belaj, F.; Jancik, V.; Herbst-Irmer, R.; MöschZanetti, N. C. Oxo-molybdenum and oxo-tungsten complexes of Schiff bases relevant to molybdoenzymes. Dalton Trans. 2009, 5655-5665.

(7) Judmaier, M. E.; Holzer, C.; Volpe, M.; Mösch-Zanetti, N. C. Molybdenum(VI) Dioxo Complexes Employing Schiff Base Ligands with an Intramolecular Donor for Highly Selective Olefin Epoxidation. Inorg. Chem. 2012, 51, 9956-9966.

(8) Judmaier, M. E.; Sala, C. H.; Belaj, F.; Volpe, M.; MöschZanetti, N. C. Dimeric $\mu$-oxo bridged molybdenum(vi) dioxo complexes as catalysts in the epoxidation of internal and terminal alkenes. New J. Chem. 2013, 37, 2139.

(9) Schachner, J. A.; Traar, P.; Sala, C.; Melcher, M.; Harum, B. N.; Sax, A. F.; Volpe, M.; Belaj, F.; Mösch-Zanetti, N. C. Dioxomolybdenum(VI) Complexes with Pyrazole Based Aryloxide Ligands: Synthesis, Characterization and Application in Epoxidation of Olefins. Inorg. Chem. 2012, 51, 7642-7649.

(10) Dupé, A.; Hossain, M. K.; Schachner, J. A.; Belaj, F.; Lehtonen, A.; Nordlander, E.; Mösch-Zanetti, N. C. Dioxomolybdenum(VI) and -Tungsten(VI) Complexes with Multidentate Aminobisphenol Ligands as Catalysts for Olefin Epoxidation. Eur. J. Inorg. Chem. 2015, 3572-3579.

(11) Arzoumanian, H.; Petrignani, J. F.; Pierrot, M.; Ridouane, F.; Sanchez, J. Preparation of an oxoperoxocyanomolybdate(VI) complex by dioxygen oxidation of an oxocyanomolybdate(IV) anion. Structure and reactivity toward phosphines and olefins. Inorg. Chem. 1988, 27, 3377-3381.

(12) Tachibana, J.; Imamura, T.; Sasaki, Y. Synthesis and characterization of a novel dioxygen complex of molybdenum porphyrin. J. Chem. Soc., Chem. Commun. 1993, 1436-1438.

(13) Minato, M.; Zhou, D.-Y.; Sumiura, K.-i.; Oshima, Y.; Mine, S.; Ito, T.; Kakeya, M.; Hoshino, K.; Asaeda, T.; Nakada, T. et al. Reactivity Patterns of O $2, \mathrm{CO} 2$, Carboxylic Acids, and Triflic Acid with Molybdenum Silyl Hydrido Complexes Bearing Polydentate Phosphinoalkyl-Silyl Ligands: Pronounced Effects of Silyl Ligands on Reactions. Organometallics 2012, 31, 49414949.

(14) Lyashenko, G.; Saischek, G.; Pal, A.; Herbst-Irmer, R.; Mösch-Zanetti, N. C. Molecular oxygen activation by a molybdenum(IV) monooxo bis( $\beta$-ketiminato) complex. Chem. Commun. 2007, 701-703.
(15) Dupé, A.; Judmaier, M. E.; Belaj, F.; Zangger, K.; MöschZanetti, N. C. Activation of molecular oxygen by a molybdenum complex for catalytic oxidation. Dalton Trans. 2015, 44, 2051420522.

(16) Zwettler, N.; Judmaier, M. E.; Strohmeier, L.; Belaj, F.; Mösch-Zanetti, N. C. Oxygen activation and catalytic aerobic oxidation by Mo(iv)/(vi) complexes with functionalized iminophenolate ligands. Dalton Trans. 2016, 45, 14549-14560.

(17) Mösch-Zanetti, N. C.; Wurm, D.; Volpe, M.; Lyashenko, G.; Harum, B.; Belaj, F.; Baumgartner, J. Replacement of an Oxo by an Imido Group in Oxotransferase Model Compounds: Influence on the Oxygen Atom Transfer. Inorg. Chem. 2010, 49, 89148921.

(18) Volpe, M.; Mösch-Zanetti, N. C. Molybdenum(VI) Dioxo and Oxo-Imido Complexes of Fluorinated $\beta$-Ketiminato Ligands and Their Use in OAT Reactions. Inorg. Chem. 2012, 51, 14401449 .

(19) Arumuganathan, T.; Volpe, M.; Harum, B.; Wurm, D.; Belaj, F.; Mösch-Zanetti, N. C. Unusual nonoctahedral geometry with molybdenum oxoimido complexes containing eta2pyrazolate ligands. Inorg. Chem. 2012, 51, 150-156.

(20) Bagherzadeh, M.; Amini, M.; Ellern, A.; Woo, L. K. Catalytic efficiency of a novel complex of oxoperoxo molybdenum(VI): Synthesis, X-ray structure and alkane oxidation. Inorg. Chem. Commun. 2012, 52-55.

(21) Bagherzadeh, M.; Zare, M.; Amani, V.; Ellern, A.; Keith Woo, L. Dioxo and oxo-peroxo molybdenum(VI) complexes bearing salicylidene 2-picoloyl hydrazone: Structures and catalytic performances. Polyhedron 2013, 53, 223-229.

(22) Merkoulov, A.; Harms, K.; Sundermeyer, J. Synthesis and Investigations of the Crystal Structure of aDinuclear Diazadiene Molybdenum Oxo-Imido Complex with a Unique N3Mo( $\mu$ O)2MoN3 Core. Eur. J. Inorg. Chem. 2005, 2005, 4902-4906.

(23) Ramnauth, R.; Al-Juaid, S.; Motevalli, M.; Parkin, B. C.; Sullivan, A. C. Synthesis, structure, and catalytic oxidation chemistry from the first oxo-imido Schiff base metal complexes. Inorg. Chem. 2004, 43, 4072-4079.

(24) Galindo, A.; Montilla, F.; Pastor, A.; Carmona, E.; Gutiérrez-Puebla, E.; Monge, A.; Ruiz, C. Synthesis and Characterization of $(2,4,6$-Trimethylphenylimido)molybdenum Complexes. Xray Crystal Structures of (L(OEt)) $\mathrm{Mo}(\mathrm{Nmes})_{2} \mathrm{Cl}$,

(L(OEt)) Mo(Nmes)Cl 2 , and $\mathrm{MoCl}_{3}(\mathrm{Nmes})($ depe $)$ (mes = 2,4,6Trimethylphenyl, L $(\mathrm{OEt})=\left(\eta-\mathrm{C}_{5} \mathrm{H}_{5}\right) \mathrm{Co}\left\{\mathrm{P}(\mathrm{O})(\mathrm{OEt})_{2}\right\}_{3}$, depe $=$ $\left.\mathrm{Et}_{2} \mathrm{PCH}_{2} \mathrm{CH}_{2} \mathrm{PEt}_{2}\right)$. Inorg. Chem. 1997, 36, 2379-2385.

(25) Knight, P. D.; Clarkson, G.; Hammond, M. L.; Kimberley, B. S.; Scott, P. Radical and migratory insertion reaction mechanisms in Schiff base zirconium alkyls. J. Organomet. Chem. 2005 $690,5125-5144$

(26) Alesso, G.; Sanz, M.; Mosquera, M. E. G.; Cuenca, T. Monocyclopentadienyl Phenoxido-Amino and Phenoxido-Amido Titanium Complexes: Synthesis, Characterisation, and Reactivity of Asymmetric Metal Centre Derivatives. Eur. J. Inorg. Chem. 2008, 2008, 4638-4649.

(27) Cross, W. B.; Anderson, J. C.; Wilson, C.; Blake, A. J. Molybdenum oxo-imido aryloxide complexes: oxo analogues of olefin metathesis catalysts. Inorg. Chem. 2006, 45, 4556-4561. (28) Reynolds, M. S.; Butler, A. Oxygen-17 NMR, Electronic, and Vibrational Spectroscopy of Transition Metal Peroxo Complexes: Correlation with Reactivity. Inorg. Chem. 1996, 35, 2378 2383.

(29) Pastor, A.; Montilla, F.; Galindo, A. Oxido- versus imidotransfer reactions in oxido-imido molybdenum(VI) complexes: A combined experimental and theoretical study. Polyhedron 2015, 90, 233-238.

(30) Mayer, J. M. Metal-oxygen multiple bond lengths: A statistical study. Inorg. Chem. 1988, 27, 3899-3903. 
(31) Zwettler, N.; Dupé, A.; Schachner, J. A.; Belaj, F.; MöschZanetti, N. C. Templated C-C and C-N Bond Formation Facilitated by a Molybdenum(VI) Metal Center. Inorg. Chem. 2015, 54, 11969-11976.

(32) Perdew, J.P., Burke, K., Ernzerhof, M. Generalized Gradient Approximation Made Simple. Phys. Rev. Lett. 1996, 77, 38653868.

(33) Perdew, J. P. Density-functional approximation for the correlation energy of the inhomogeneous electron gas. Phys. Rev. B, Condens. Matter 1986, 33, 8822-8824.

(34) Foster, J. P.; Weinhold, F. Natural hybrid orbitals. J. Am. Chem. Soc. 1980, 102, 7211-7218.

(35) Reed, A. E.; Weinhold, F. Natural bond orbital analysis of near-Hartree-Fock water dimer. J. Chem. Phys. 1983, 78, 40664073.

(36) Reed, A. E., Weinstock, R.B., Weinhold, F. Natural population analysis. J. Chem. Phys. 1985, 83, 735-746.

(37) Reed, A. E.; Curtiss, L. A.; Weinhold, F. Intermolecular interactions from a natural bond orbital, donor-acceptor viewpoint. Chem. Rev. 1988, 88, 899-926.

(38) Carpenter, J. E.; Weinhold, F. Analysis of the geometry of the hydroxymethyl radical by the "different hybrids for different spins" natural bond orbital procedure. J. Mol. Struct. Theochem 1988, 169, 41-62.

(39) Wiberg, K. B. Application of the pople-santry-segal CNDO method to the cyclopropylcarbinyl and cyclobutyl cation and to bicyclobutane. Tetrahedron 1968, 24, 1083-1096.

(40) Tantirungrotechai, Y.; Phanasant, K.; Roddecha, S.; Surawatanawong, P.; Sutthikhum, V.; Limtrakul, J. Scaling factors for vibrational frequencies and zero-point vibrational energies of some recently developed exchange-correlation functionals. Journal of Molecular Structure: THEOCHEM 2006, 760, 189-192. 
Synopsis. Activation of molecular dioxygen at a Mo(IV) imido compound led to the isolation and full characterization of a remarkably stable transition metal imido peroxido complex.
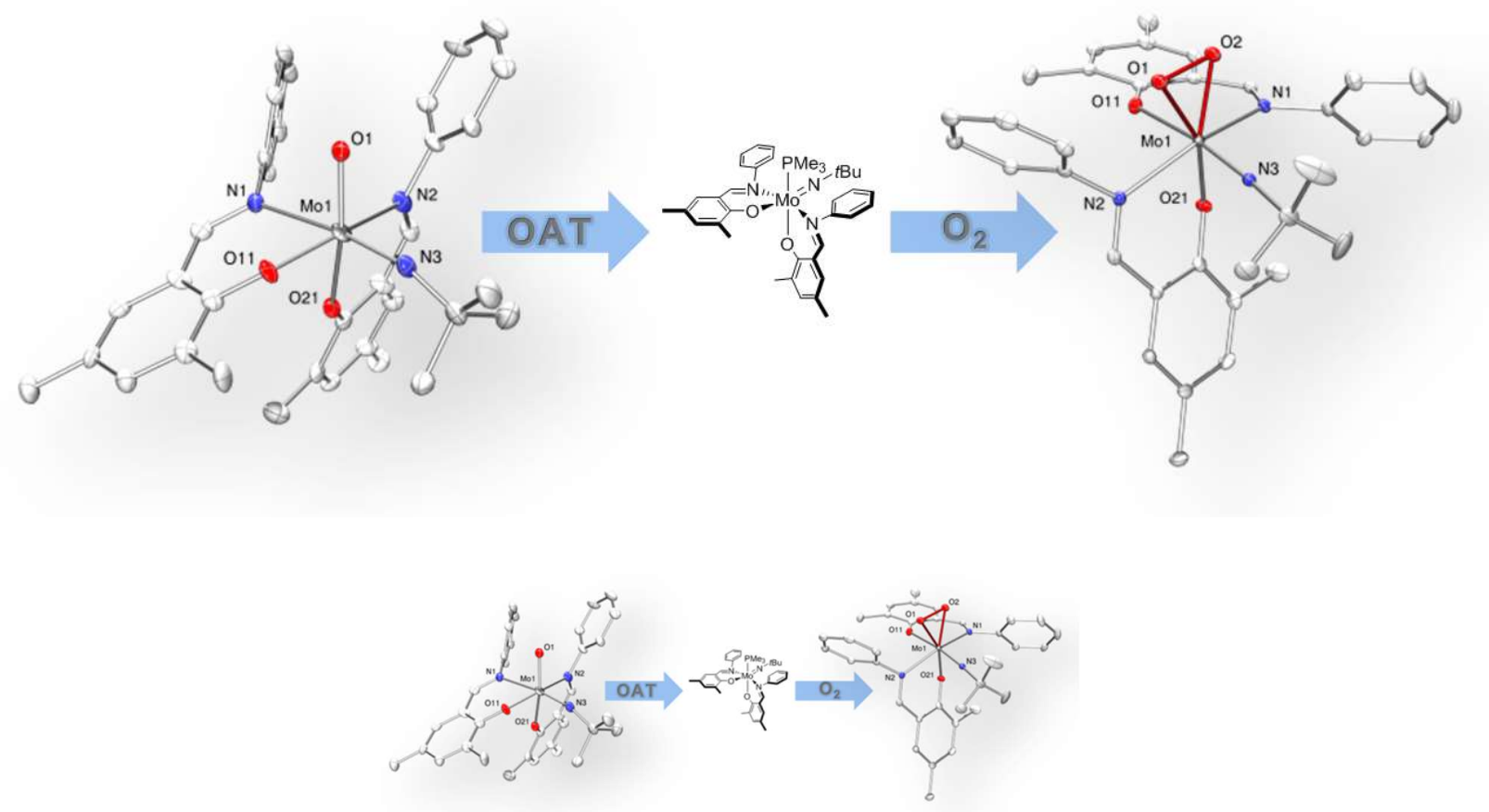